University of Nebraska - Lincoln

DigitalCommons@University of Nebraska - Lincoln

2005

Radius of Gyration of Polystyrene Combs and Centipedes in a $\boldsymbol{\Theta}$

Solvent

Ken Terao

Brandon S. Farmer

Yo Nakamura

Hermis latrou

Kunlun Hong

See next page for additional authors

Follow this and additional works at: https://digitalcommons.unl.edu/usdoepub

Part of the Bioresource and Agricultural Engineering Commons

Terao, Ken; Farmer, Brandon S.; Nakamura, Yo; latrou, Hermis; Hong, Kunlun; and Mays, Jimmy W., "Radius of Gyration of Polystyrene Combs and Centipedes in a $\Theta$ Solvent" (2005). US Department of Energy Publications. 58.

https://digitalcommons.unl.edu/usdoepub/58

This Article is brought to you for free and open access by the U.S. Department of Energy at DigitalCommons@University of Nebraska - Lincoln. It has been accepted for inclusion in US Department of Energy Publications by an authorized administrator of DigitalCommons@University of Nebraska - Lincoln. 


\section{Authors}

Ken Terao, Brandon S. Farmer, Yo Nakamura, Hermis latrou, Kunlun Hong, and Jimmy W. Mays 


\title{
Radius of Gyration of Polystyrene Combs and Centipedes in a $\Theta$ Solvent
}

\author{
Ken Terao,,,,,,$+ \#$ Brandon S. Farmer, ${ }^{*, \dagger}$ Yo Nakamura, ${ }^{\dagger, \S}$ Hermis Iatrou, \\ Kunlun Hong, ${ }^{\perp}$ and Jimmy W. Mays $*, \dagger, \perp$, I
}

\begin{abstract}
Department of Chemistry, University of Tennessee, 552 Buehler Hall, Knoxville, Tennessee 37996-1600, Department of Biological and Chemical Engineering, Gunma University, Kiryu, Gunma 376-8515, Japan, Department of Polymer Chemistry, Kyoto University, Nishikyo-ku, Kyoto, 615-8510, Japan, Department of Chemistry, University of Athens, Panepistimiopolis, Zografou, 15771 Athens, Greece, and Chemical Sciences Division, Oak Ridge National Laboratory, Oak Ridge, Tennessee 37831-6197
\end{abstract}

Received March 16, 2004; Revised Manuscript Received December 2, 2004

\begin{abstract}
The molecular weight dependence of the radii of gyration $R_{\mathrm{g}}$ in a $\Theta$ solvent (trans-decalin) of one regular branched comb and three regular centipede polystyrenes was studied using a gel permeation chromatography system equipped with a two-angle light scattering detector and a refractive index detector. $R_{\mathrm{g}}$ in trans-decalin for each sample of particular molecular weight was about $25 \%$ smaller than that in a good solvent (tetrahydrofuran, THF). On the other hand, they are 20-40\% larger than the theoretical values from the Gaussian chain model. This difference can be explained with the wormlike comb model developed by Nakamura et al. (Macromolecules 2000, 33, 8323-8328). Persistence lengths thus obtained for each sample were about half of that determined in THF solution. However, they are significantly larger than that for linear polystyrene. These results suggest that a main chain stiffening effect exists in comb polystyrenes even in a $\Theta$ solvent.
\end{abstract}

\section{Introduction}

Solution properties of branched polymers have been investigated theoretically and experimentally. The most essential model to explain their unperturbed radius of gyration $R_{\mathrm{g}}$ is that based on an assumption of a Gaussian distribution of chain segments. ${ }^{1}$ This model reproduced $R_{\mathrm{g}}$ almost quantitatively for 3-, 4-, and 6 -arm star polymers with the molecular weight of each side chain being more than $10000 .^{2-4}$ However, $R_{\mathrm{g}}$ for star polymers with more arms and comb polymers were found to be systematically larger than the calculated values. ${ }^{2,5-9}$ This was explained by considering that such branched polymers expand due to the high segment densities. Because comb polymers synthesized at that time had a large distribution in the interval between neighboring side chains, it is desirable to use the polymer having more controlled structure in order to investigate this phenomenon quantitatively.

The first comb polymer having a constant interval between two neighboring side chains was synthesized by polymerization of macromonomers. ${ }^{10,11}$ Some groups ${ }^{12-20}$ found that the main chain of the polymacromonomers behaves as a stiff polymer due to the repulsive force between the side chains as well as that between the main chain and side chain, and that the Kuhn segment length $\lambda^{-1}$ increases with increasing the side chain length. This trend is seen even in a $\Theta$ solvent. ${ }^{16-20}$ Birshtein and co-workers ${ }^{21,22}$ evaluated the contribution from the excluded-volume effect to $\lambda^{-1}$ for comb polymers in $\Theta$ solvents. They found that $\lambda^{-1}$ is

\footnotetext{
$\dagger$ University of Tennessee.

$\$$ Gunma University.

$\S$ Kyoto University.

"University of Athens.

${ }^{\perp}$ Oak Ridge National Laboratory.

\# E-mail: terao@bce.gunma-u.ac.jp.

I E-mail: jimmymays@utk.edu.
}

proportional to the 1.375 th power of the side chain length, however, it is not easy to compare with experimental data due to no numerical constant being included in this expression. ${ }^{21,22}$ Very recently, Nakamura and Norisuye ${ }^{23}$ developed another theoretical work to explain the stiffness of polymacromonomers in good and $\Theta$ solvents and found that the total Kuhn segment length $\lambda^{-1}$ for the main chain can be expressed as the sum of the Kuhn's segment length $\lambda_{0}{ }^{-1}$ and $\lambda_{\mathrm{b}}{ }^{-1}$ from short and long range interactions, respectively. The first term is a constant depending only on the local chemical structure near each junction point and the second term $\lambda_{\mathrm{b}}{ }^{-1}$ was evaluated without unknown constants and it is proportional to the squared molecular weight of the side chain. However, this theoretical prediction was not confirmed completely because the side chain density of polymacromonomers was too high and $\lambda_{0}{ }^{-1}$ was much larger than $\lambda^{-1}$ for linear polystyrene. This result suggests that comb chains with longer and constant intervals between each junction point should be used to investigate the influence of side chains to the conformation of the main chain.

Recently, a new scheme to make comblike polymers was developed, ${ }^{24,25}$ and comb polymers with fixed side chain length and controlled spacing between nearest neighboring side chains were obtained by the reaction of $\alpha, \omega$-dianionic polymer chains (connectors) with dichlorosilane end-functionalized side chains in a polycondensation reaction. By modification of this strategy, polystyrene centipedes which have two side chains at each junction point were also synthesized. Nakamura et al. ${ }^{25}$ reported the molecular weight dependence of $R_{\mathrm{g}}$ in tetrahydrofuran (THF) and determined that the main chains of these polymers are much stiffer than that for linear polystyrene. In particular, it was very interesting to investigate the dimensional properties for centipede polymers because no solution data had been reported 


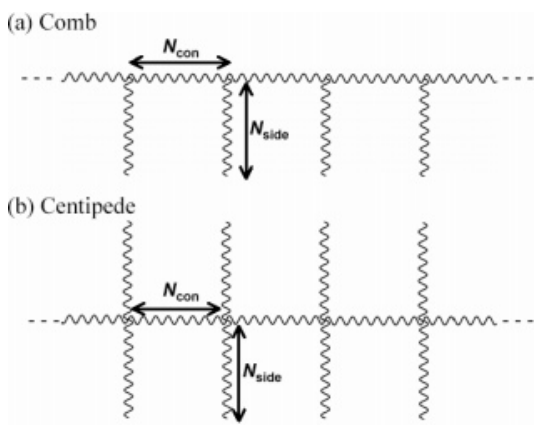

Figure 1. Schematic representation of comb and centipede polymers.

Table 1. Molecular Parameters for Branched Polymers ${ }^{a}$

\begin{tabular}{|c|c|c|c|}
\hline & $N_{\text {side }}$ & $N_{\text {con }}$ & $f$ \\
\hline $\mathrm{CS} 25-35^{a}$ & 338 & 222 & 3 \\
\hline GS15-35 & 331 & 151 & 4 \\
\hline GS40-25 & 277 & 396 & 4 \\
\hline GS60-15 & 130 & 548 & 4 \\
\hline
\end{tabular}

${ }^{a}$ Reference $24 .{ }^{b}$ Reference 25 .

previously. Therefore, to clarify the long-range interaction in $\lambda^{-1}$, molecular weight dependence of the radius of gyration $R_{\mathrm{g}}$ in a $\Theta$ solvent (trans-decalin) of one regular branched comb and three centipede polystyrenes was studied using a gel permeation chromatography system equipped with a two-angle light scattering detector.

\section{Experimental Section}

A comb polystyrene CS25-35 and three polystyrene centipedes GS15-35, GS40-25, and GS60-15 prepared previously $^{24,25}$ were chosen for this study, and their topological structures are depicted in Figure 1 . Their number $N_{\text {side }}$ of monomer units for each side chain, that $N_{\text {con }}$ for each connector, and the functionality $f$ at each junction point on the main chain are shown in Table 1; i.e. the number of side chains at the junction point is $f-2(f=3$ for the comb and $f=4$ for the centipede). Molecular weight dependence of $R_{\mathrm{g}}$ in trans-decalin at $22{ }^{\circ} \mathrm{C}$ was determined using a Polymer Laboratories PLGPC-120 GPC system with a Precision detectors PD-2040 twoangle $\left(15\right.$ and $\left.90^{\circ}\right)$ light scattering (TALS) photometer with a $680 \mathrm{~nm}$ laser and a refractive index detector. These angles are equivalent to $0.13 \times 10^{-2}$ and $3.69 \times 10^{-2} \mathrm{~nm}^{-2}$, respectively, in the squared scattering vector $k^{2}$. Injected polymers were fractionated by two Polymer Laboratories PL-Gel mixed bed $10 \mu \mathrm{m}$ columns $(300 \times 7.5 \mathrm{~mm})$, connected in series and set to $110^{\circ} \mathrm{C}$ to avoid adsorption of the polymer to the column, before measuring light scattering and excess refractive index. The accuracy of TALS for measuring $R_{\mathrm{g}}$ was recently confirmed for polystyrenes in various solvents over an appropriate range of $R_{\mathrm{g}}{ }^{26,27}$ Theoretically, this range is where $R_{\mathrm{g}}$ is less than about $70 \mathrm{~nm}$ for our system when Berry's square root method ${ }^{28}$ is applied. A standard polystyrene sample whose weightaverage molecular weight $M_{\mathrm{w}}$ was determined with a Wyatt Technology DAWN EOS to be 65000 was used to calibrate the two-angle light scattering detector. For the experimental details and data processing, consult ref 26 .

\section{Results and Discussion}

The curves of the polymer mass concentration $c, M_{\mathrm{w}}$, and $R_{\mathrm{g}}$ are shown against the elution volume $V_{\mathrm{e}}$ for GS40-25 in Figure 2. It is seen that this sample was fractionated well in the $\Theta$ solvent. We used the $M_{\mathrm{w}}$ and $R_{\mathrm{g}}$ data thus obtained for the following analysis over the range of elution volume where both the concentration and the scattering intensity are more than $10 \%$ of the value at the peak and $R_{\mathrm{g}}$ thus obtained is more than

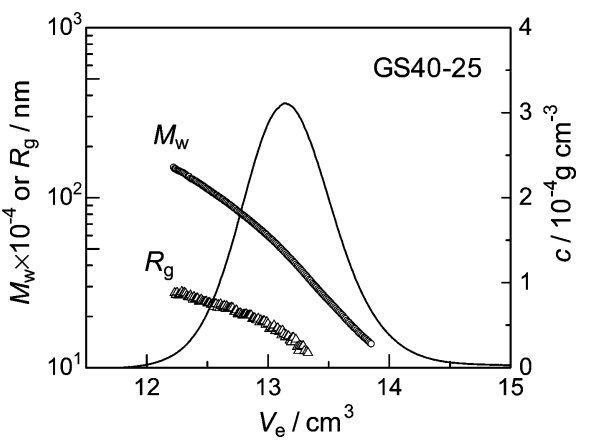

Figure 2. Plots of $M_{\mathrm{w}}, R_{\mathrm{g}}$, and $c$ vs $V_{\mathrm{e}}$ for polystyrene centipede GS40-25.

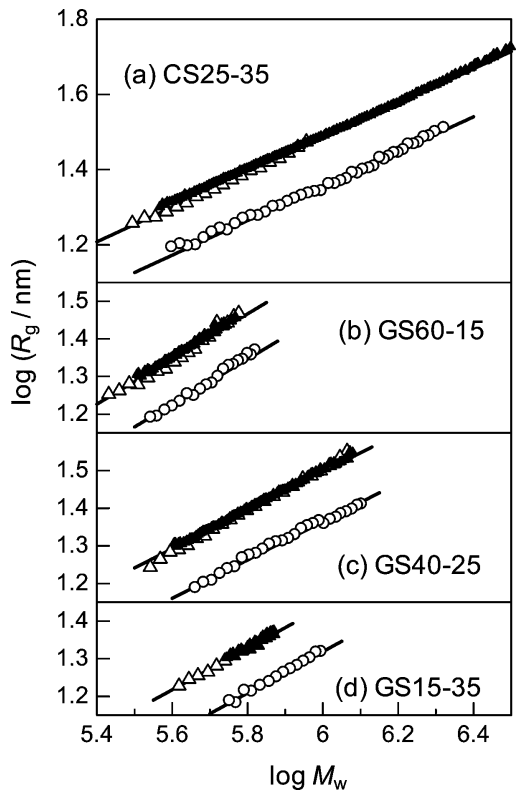

Figure 3. Molecular weight dependence of $R_{\mathrm{g}}$ for CS25-35, GS60-15, GS40-25, and GS15-35 in trans-decalin at $22{ }^{\circ} \mathrm{C}$ (circles) and in THF at $25^{\circ} \mathrm{C}$ (filled triangles: Nakamura et al., ${ }^{25}$ open triangles: Terao and Mays ${ }^{26}$ ).

$15 \mathrm{~nm}$. This corresponds to $12.4<V_{\mathrm{e}}<13.2 \mathrm{~cm}^{3}$ for GS40-25 in Figure 2. Molecular weight dependence of $R_{\mathrm{g}}$ for CS25-35, GS15-35, GS40-25, and GS60-15 in trans-decalin at $22{ }^{\circ} \mathrm{C}$ is illustrated in Figure 3 along with the data for THF solutions studied previously with the data from a multiangle light scattering detector ${ }^{25}$ and TALS. ${ }^{26}$ It is seen that data from TALS do not exceed the upper limit for determining $R_{\mathrm{g}}: 70 \mathrm{~nm}$. While the slope is irrespective of the solvent, $R_{\mathrm{g}}$ for each polymer in trans-decalin is about $25 \%$ smaller than that in THF due to smaller repulsive forces among segments of a polymer in the $\Theta$ solvent.

Figure 4 shows the molecular-weight dependence of $R_{\mathrm{g}}$ for regular branched polystyrenes in trans-decalin at $22{ }^{\circ} \mathrm{C}$ along with literature values ${ }^{26,29-31}$ for linear polystyrene near the $\Theta$ temperature $20.4 \sim 24{ }^{\circ} \mathrm{C}$. The temperature is the $\Theta$ temperature of linear polystyrene in trans-decalin, ${ }^{29-31}$ and the actual $\Theta$ temperature for our branched polystyrene samples may be quite close to the linear polystyrene because phase separation was observed for dilute solutions at the room temperature $\left(18^{\circ} \mathrm{C}\right)$ for CS25-35 and GS60-15 in trans-decalin. The radii of gyration $R_{\mathrm{g}, \mathrm{b}}$ for branched polymers are slightly smaller than those for linear polystyrene, $R_{\mathrm{g}, 1}$. This phenomenon is generally seen for branched polymers. ${ }^{2-9}$ Assuming Gaussian bond probability, the ratio $g_{\mathrm{s}}$ of $R_{\mathrm{g}, \mathrm{b}}$ to $R_{\mathrm{g}, 1}$ for the comb polymer having $p$ junction points is 


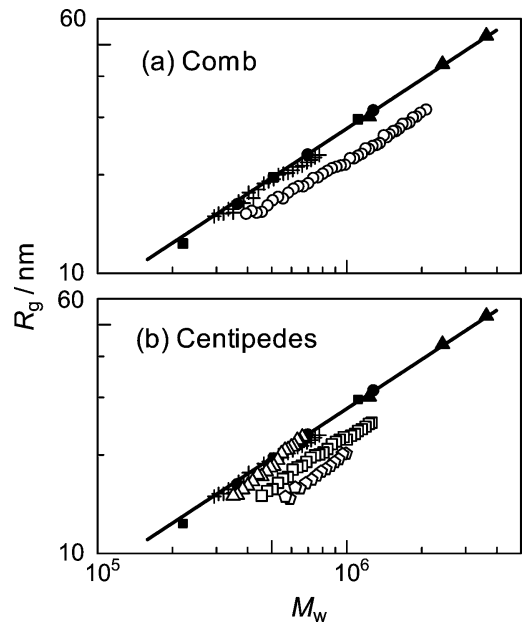

Figure 4. Molecular weight dependence of $R_{\mathrm{g}}$ for linear and regularly branched polystyrenes in trans-decalin at $22{ }^{\circ} \mathrm{C}$. CS25-35 (open circles), GS60-15 (open triangles), GS40-25 (open squares), GS15-35 (open pentagons), and linear polystyrene (crosses, Terao and Mays ${ }^{26}$ filled squares, Inagaki et al..$^{29}$ at $24^{\circ} \mathrm{C}$; filled triangles, Fukuda et al. ${ }^{30}$ at $20.4^{\circ} \mathrm{C}$; filled circles, Konishi et al..$^{31}$ at $21^{\circ} \mathrm{C}$ ).

expressed with the ratio $r$ of $N_{\text {side }}$ to $N_{\text {con }}$ as

$$
g_{\mathrm{s}}=\frac{\begin{array}{r}
p(3 p-2) r^{3}+p(p+1)(p+2) r^{2}+ \\
p(p+1)(2 p+1) r+(p+1)^{3}
\end{array}}{(r p+p+1)^{3}}
$$

for normal comb polymers by Berry and Orofino ${ }^{32}$ and

$$
\begin{aligned}
& g_{\mathrm{s}}= \\
& \frac{4 p(3 p-1) r^{3}+2 p(p+1)(2 p+1) r(r+1)+(p+1)^{3}}{(2 r p+p+1)^{3}}
\end{aligned}
$$

for the polymer centipede by Nakamura et al. ${ }^{25}$ Dashed lines in Figure 5 shows the theoretical values calculated from eqs 1 and 2 and the relation

$$
R_{\mathrm{g}, \mathrm{l}}=0.0277 M_{\mathrm{w}}^{1 / 2}
$$

for linear polystyrene with narrow molecular weight distributions in trans-decalin at the $\Theta$ temperature ${ }^{26}$ The solid line in each panel of Figure 4 shows the calculated values from the equation. Experimental values (circles) for each polymer are about $20 \%$ (for CS25-35, GS60-15, and GS45-25) and 40\% (for GS1535) larger than the theoretical curves for the Gaussian distribution. This difference shows unmistakably that the main chain of these polymers has an extended conformation even in the $\Theta$ solvent.

To consider the main chain stiffness effect on $R_{\mathrm{g}}$, Nakamura et al. ${ }^{25}$ also calculated $R_{\mathrm{g}}$ for the wormlike comb polymer whose main chain and side chain having Kuhn segment lengths $\lambda^{-1}$ and $\lambda_{\mathrm{s}}{ }^{-1}$, respectively, as follows ${ }^{25}$

$$
R_{\mathrm{g}}=g\left(L, L_{\mathrm{s}}, \lambda, \lambda_{\mathrm{s}}, p, f\right)
$$

where $g\left(L, L_{\mathrm{s}}, \lambda, \lambda_{\mathrm{s}}, p, f\right)$ is known as a function of $L, L_{\mathrm{s}}, \lambda$, $\lambda_{\mathrm{s}}, p$, and $f . L$ and $L_{\mathrm{s}}$ are the contour length of the main chain and the side chain, respectively. It should be noted

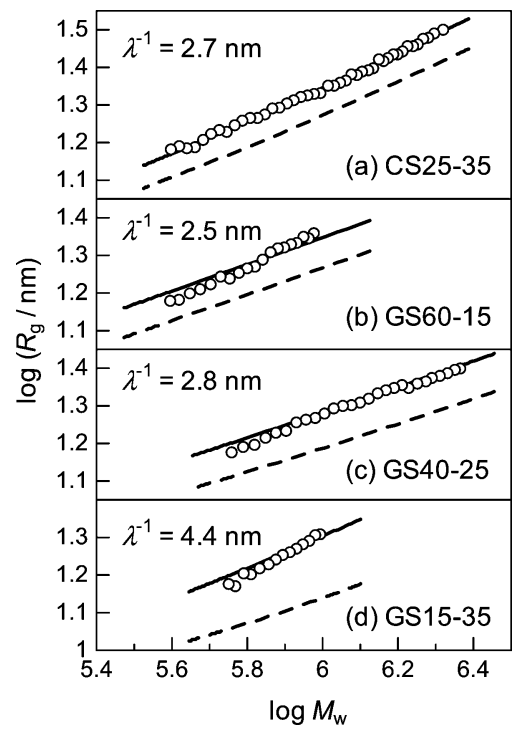

Figure 5. Comparison between the measured $R_{\mathrm{g}}$ for indicated regularly branched polystyrenes in trans-decalin at $22^{\circ} \mathrm{C}$ and

\begin{tabular}{|c|c|c|}
\hline & $\begin{array}{c}\lambda^{-1} / \mathrm{nm} \text { in } \\
\text { trans-decalin }^{a}\end{array}$ & $\begin{array}{c}\lambda^{-1 / \mathrm{nm}^{-}} \\
\text {in } \mathrm{THF}^{b}\end{array}$ \\
\hline CS25-35 & $2.7 \pm 0.1$ & 5.5 \\
\hline GS15-35 & $4.4 \pm 0.3$ & 8.5 \\
\hline GS40-25 & $2.8 \pm 0.2$ & 5.5 \\
\hline GS60-15 & $2.5 \pm 0.2$ & 4.5 \\
\hline
\end{tabular}
the theoretical values (solid lines) calculated for the flexible discrete comb (dashed line) and the wormlike comb model (solid line).

Table 2. Kuhn Segment Length of the Main Chain for Polystyrene Comb and Centipedes

$a$ These values were determined the curve fitting method with eq $4 .{ }^{b}$ Reference 25 .

that $L$ and $L_{\mathrm{s}}$ were calculated with the contour length $h$ per styrene monomer unit. This equation should be used for comb polymers in $\Theta$ solvent because the excluded-volume effect is not considered in it. We chose $0.27 \mathrm{~nm}$ for $h$ because this value was estimated for both linear polystyrene ${ }^{33}$ and the main chain of polystyrene polymacromonomers. ${ }^{16,17,20}$ On the other hand, $\lambda_{\mathrm{s}}{ }^{-1}$ was assumed to be the value for linear polystyrene $(1.8 \mathrm{~nm})$, which was estimated from eq 3 and the relation $R_{\mathrm{g}}{ }^{2}=$ $h M / 6 \lambda M_{0}$ for the wormlike chain model at the Gaussian coil limit, because the stiffness of the side chain of the comblike polymers may not be much different from that for linear polystyrene and the theoretical $R_{\mathrm{g}}$ values are not sensitive to $\lambda_{\mathrm{s}}$ in the molecular weight range of our polymer samples. Here, $M$ and $M_{0}$ are the molecular weights for polymer and monomer, respectively. The estimation of $\lambda_{\mathrm{s}}$ has been made by intrinsic viscosity, diffusion coefficient, and small-angle X-ray scattering experiments for polystyrene polymacromonomers in cyclohexane. ${ }^{18,19,20,34} \lambda^{-1}$ was estimated by a curve fitting method with eq 4 to represent our experimental $R_{\mathrm{g}}$ data, and the values are shown in Table 2 . The ratio of $\lambda^{-1}$ in the $\Theta$ solvent to that in the good solvent is between 0.5 and 0.56 . This result is very similar to known data for polymacromonomers $(0.5-0.6) \cdot{ }^{17,20}$ However, the main chain stiffening effect exists in comb polystyrenes even in the $\Theta$ solvent because they are still much higher than that for linear polystyrene $(1.8 \mathrm{~nm})$.

Nakamura and Norisuye ${ }^{23}$ conducted theoretical work to derive $\lambda^{-1}$ for comb polymers in a $\Theta$ solvent and $\lambda^{-1}$ is expressed with the Kuhn length $\lambda_{0}^{-1}$ for the short- 
range interactions (independent of the length of side chain) and $\lambda_{\mathrm{b}}{ }^{-1}$ for long-range interactions as

$$
\lambda^{-1}=\lambda_{0}^{-1}+\lambda_{\mathrm{b}}^{-1}
$$

It is expected that the long-range effect for comb polymers is more effective than those for polymacromonomers. The second term $\lambda_{\mathrm{b}}{ }^{-1}$ was derived from the increase of the free energy accompanying the bending, considering binary and ternary interactions of the side chains. If the side chain consists of $N_{\text {side }}$ units of the effective bond length $b$; this value is estimated to be 0.69 $\mathrm{nm}$ from eq 3 and $R_{\mathrm{g}}{ }^{2}=n b^{2} / 6, \lambda_{\mathrm{b}}{ }^{-1}$ is expressed $\mathrm{as}^{23}$

$$
\lambda_{\mathrm{b}}^{-1}=0.02334\left(\frac{N_{\text {side }}}{b}\right)^{2} \frac{\beta_{3}}{\left(N_{\text {con }} h\right)^{3}}
$$

for comblike polymers at the $\Theta$ point. The ternary cluster integral $\beta_{3}$ was estimated experimentally to be $4.4 \times 10^{-3} \mathrm{~nm}^{6}$ for linear polystyrene in trans-decalin around the $\Theta$ temperature. ${ }^{35}$ This value seems to be quite close even for branched polymers because $\beta_{3}$ for linear polystyrene $\left(\beta_{3}=4 \times 10^{-3} \mathrm{~nm}^{6}\right)^{36}$ in cyclohexane at the $\Theta$ temperature was reported to be as large as those for star polystyrenes ${ }^{3,4}$ in the same condition. Therefore, $\lambda_{\mathrm{b}}{ }^{-1}$ is calculated to be $1.1 \times 10^{-4} \mathrm{~nm}$ for CS25-35 from eq 6. This value is about four orders smaller than the experimental $\lambda_{\mathrm{b}}{ }^{-1}$ value, $0.9 \mathrm{~nm}$, which is estimated to be the difference in $\lambda^{-1}$ for CS25-35 and linear polystyrene. This result suggests that excluded volume interactions among three segments on the side chains are too small to explain the stiffness of comb polymers in the $\Theta$ solvent and the difference in $\lambda^{-1}$ includes at least higher order interactions and the interactions between the main chain and the side chain.

In the present study, we measured the molecular weight dependence of the radii of gyration for topologically well-defined polystyrenes (combs and centipedes) in trans-decalin at $22{ }^{\circ} \mathrm{C}$ ( $\Theta$ conditions). We found that the wormlike comb model is suitable for the polystyrene combs and centipedes even in the $\Theta$ solvent and unmistakable stiffness of the main chain was clearly observed due to the excluded volume interactions in the molecule. The Kuhn segment length estimated for each polymer was about half as large as that in THF. This ratio is close to that found for polymacromonomers consisting of polystyrene in cyclohexane (a $\Theta$ solvent) and toluene (a good solvent), however the absolute values of $\lambda^{-1}$ were not explained by the known theories.

Acknowledgment. Research sponsored by the Division of Materials Sciences and Engineering, Office of Basic Energy Sciences, U.S. Department of Energy, under Contract No. DE-AC05-00OR22725 with Oak Ridge National Laboratory, managed and operated by UT-Battelle, LLC. K.T. thanks Professor Marek Pyda of the University of Tennessee at Knoxville for valuable discussions about the GPC system. We thank the National Science Foundation (DMR-0216816) and the
Tennessee Advanced Materials Laboratory for the purchase of the GPC and light scattering systems used in this work.

\section{References and Notes}

(1) Yamakawa, H. Modern Theory of Polymer Solutions; Harper \& Row: New York, 1971.

(2) Douglas, J. F.; Roovers, J.; Freed, K. F. Macromolecules 1990, 23, 4168-4180 and references therein.

(3) Okumoto, M.; Terao, K.; Nakamura, Y.; Norisuye, T.; Teramoto, A. Macromolecules 1997, 30, 7493-7499.

(4) Okumoto, M.; Tasaka, Y.; Nakamura, Y.; Norisuye, T. Macromolecules 1999, 32, 7430-7436.

(5) Decker, P. D. Makromol. Chem. 1969, 125, 136-160.

(6) Noda, I.; Horikawa, T.; Kato, T.; Fujimoto, T.; Nagasawa, M. Macromolecules 1970, 3, 795-799.

(7) Berry, G. C. J. Polym. Sci., Polym. Phys. Ed. 1971, 9, 687715.

(8) Candau, F.; Rempp, P. Eur. Polym. J. 1972, 8, 757-768.

(9) Strazielle, C.; Herz, J. Eur. Polym. J. 1977, 13, 223-233.

(10) Tsukahara, Y.; Mizuno, K.; Segawa, A.; Yamashita, Y. Macromolecules 1989, 22, 1546-1552.

(11) Tsukahara, Y.; Tsutsumi, K.; Yamashita, Y.; Shimada, S. Macromolecules 1990, 23, 5201-5208.

(12) Wintermantel, M.; Schmidt, M.; Tsukahara, Y.; Kajiwara, Y.; Kohjiya, S. Macromol. Rapid Commun. 1994, 15, 279-284.

(13) Nemoto, N.; Nagai, M.; Koike, A.; Okada, S. Macromolecules 1995, 28, 3854-3859.

(14) Wintermantel, M.; Gerle, M.; Fischer, K.; Schmidt, M.; Wataoka, I.; Urakawa, H.; Kajiwara, K.; Tsukahara, Y. Macromolecules 1996, 29, 978-983.

(15) Kawaguchi, S.; Akaike, K.; Zhang, Z.-M.; Matsumoto, H.; Ito, K. Polym. J. 1998, 30, 1004-1007.

(16) Terao, K.; Takeo, Y.; Tazaki, M.; Nakamura, Y.; Norisuye, T. Polym. J. 1999, 31, 193-198.

(17) Terao, K.; Nakamura, Y.; Norisuye, T. Macromolecules 1999 , $32,711-716$.

(18) Terao, K.; Hokajo, T.; Nakamura, Y.; Norisuye, T. Macromolecules 1999, 32, 3690-3694.

(19) Terao, K.; Hayashi, S.; Nakamura, Y.; Norisuye, T. Polym. Bull. (Berlin) 2000, 44, 309-316.

(20) Hokajo, T.; Terao, K.; Nakamura, Y.; Norisuye, T. Polym. J. 2001, 33, 481-485.

(21) Birshtein, T. M.; Borisov, O. V.; Zhulina, Ye. B.; Khokolov, A. R.; Yurasova, T. A. Polym. Sci. U.S.S.R. 1987, 29, 12931300 .

(22) Zhulina, E. B.; Vilgis, T. A. Macromolecules 1995, 28, 10081015.

(23) Nakamura, Y.; Norisuye, T. Polym. J. 2001, 33, 874-878.

(24) Iatrou, H.; Mays, J. W.; Hadjichristidis, N. Macromolecules 1998, 31, 6697-6701.

(25) Nakamura, Y.; Wan, Y.; Mays, J. W.; Iatrou, H.; Hadjichristidis, N. Macromolecules 2000, 33, 8323-8328; Macromolecules 2001, 34, 2018.

(26) Terao, K.; Mays, J. W. Eur. Polym. J. 2004, 40, 1623-1627.

(27) Liu, Y.; Bo, S.; Zhu, Y.; Zhang, W. Polymer 2003, 44, 72097220.

(28) Berry, G. C. J. Chem. Phys. 1966, 44, 4550-4564.

(29) Inagaki, H.; Suzuki, H.; Fujii, M.; Matsuo, T. J. Phys. Chem. 1966, 70, 1718-1726.

(30) Fukuda, M.; Fukutomi, M.; Kato, Y.; Hashimoto, T. J. Polym. Sci.: Polym. Phys. Ed. 1974, 12, 871-890.

(31) Konishi, T.; Yoshizaki, T.; Yamakawa, H. Macromolecules 1991, 24, 5614-5622.

(32) Berry, G. C.; Orofino, T. A. J. Chem. Phys. 1964, 40, 16141621.

(33) Norisuye, T.; Fujita, H. Polym. J. 1982, 14, 143-147.

(34) Nakamura, Y.; Amitani, K.; Terao, K.; Norisuye, T. Kobunshi Ronbunshu 2003, 60, 174-180.

(35) Nakamura, Y.; Inoue, N.; Norisuye, T.; Teramoto, A. Macromolecules 1997, 30, 631-636.

(36) Nakamura, Y.; Norisuye, T.; Teramoto, A. Macromolecules 1991, 24, 4904-4908.

MA049485S 